\title{
Annual Report October 1994 to September 1995
}

This has been the busiest year in the history of the journal. The total number of papers submitted to Thorax has increased by $20 \%$ over the last year to a record number of 872 manuscripts. The journal has attempted to cope with this increase in work by printing more pages than in previous years. We now print up to 104 pages per issue and hopefully next year the number will increase yet again.

Table 1 shows the articles submitted by category over the last four years. It is particularly gratifying that the major increase has been in original papers and short papers rather than case reports. The short papers have proved to be a particularly popular means of communication for new or preliminary work and negative studies. We have managed to maintain three editorials per issue, including an increasing number of directed editorials, in an attempt to highlight interesting or potentially important manuscripts.

Table 2 shows the geographical distribution of submissions which confirms that the journal continues to attract manuscripts from all over the world.

The acceptance rate for original full papers has increased a little during the last 12 months to $50.3 \%$ and for short papers it is $49 \%$, whilst for case reports it remains at $19 \%$.

Table 3 summarises the decision times for papers submitted during the current year on which a decision to accept subject to revision or to finally accept have been made. The median time for both original papers and case reports is virtually identical to last year, but the median time to a final decision for original papers is twice as long as last year. This is due to the fact that the workload has

Table 1 Articles submitted by category

\begin{tabular}{lcccc}
\hline & 1992 & 1993 & 1994 & 1995 \\
\hline Original papers & 370 & 415 & 410 & 493 \\
Case reports & 204 & 219 & 242 & 252 \\
Short papers & - & - & 14 & 48 \\
Editorials & 27 & 44 & 34 & 38 \\
Review series & 16 & 24 & 6 & 15 \\
Supplement articles & - & - & 12 & 16 \\
Case report commentaries & - & - & -3 & 7 \\
Scientific updates & -4 & - & - & -3 \\
Science matters & - & - & 721 & 872 \\
Total & 621 & 702 & 721 \\
\hline
\end{tabular}

Table 2 Geographical distribution of submissions

\begin{tabular}{lcccc}
\hline & $\begin{array}{l}1992 \\
(n=621)\end{array}$ & $\begin{array}{l}1993 \\
(n=702)\end{array}$ & $\begin{array}{l}1994 \\
(n=721)\end{array}$ & $\begin{array}{l}1995 \\
(n=872)\end{array}$ \\
\hline UK & 277 & 257 & 253 & 291 \\
Western Europe & 167 & 179 & 220 & 266 \\
Spain & 35 & 40 & 50 & 46 \\
The Netherlands & 30 & 27 & 35 & 51 \\
Italy & 9 & 21 & 28 & 38 \\
France & 17 & 18 & 19 & 27 \\
Turkey & 15 & 15 & 15 & 13 \\
Israel & 15 & 10 & 15 & 20 \\
Eire & 10 & 12 & 13 & 10 \\
Switzerland & 8 & 7 & 12 & 10 \\
Germany & 10 & 13 & 11 & 16 \\
Belgium & 7 & 9 & 9 & 17 \\
Greece & 3 & 3 & 9 & 7 \\
Austria & 7 & 4 & 3 & 7 \\
Portugal & 1 & 0 & 1 & 3 \\
Malta & - & - & - & 1 \\
USA and Canada & 48 & 81 & 100 & 101 \\
Japan & 37 & 44 & 47 & 65 \\
Australasia & 18 & 32 & 32 & 38 \\
Scandinavia & 25 & 38 & 27 & 36 \\
Asia & 32 & 35 & 22 & 34 \\
Eastern Europe & 6 & 9 & 6 & 7 \\
South America & 1 & 9 & 5 & 14 \\
Africa & 4 & 6 & 5 & 7 \\
Middle East & 6 & 12 & 4 & 13 \\
\hline
\end{tabular}

Table 3 Decision time for submitted papers, 1994-5

\begin{tabular}{lcc}
\hline & Original papers & Case reports \\
\hline Number & 363 & 215 \\
Median time to first decision (days) & 72 & 59 \\
Papers resubmitted $(\mathrm{n})$ & 120 & 19 \\
Median time to final decisions (days) & 58 & 6 \\
\hline
\end{tabular}

increased to such an extent that the Associate Editors are being asked to become much more involved in the editing of returned manuscripts. The size of the task has become too large for the Editor to handle himself.

The impact factors for the thoracic journals have hardly changed in 1994. Thorax has dropped slightly from 2.4 to $2 \cdot 2$ but remains just ahead of the European Respiratory Fournal in third position behind the American fournal of Respiratory and Critical Care Medicine and the "Red" journal.

1995 has seen several innovations. The case reports are now usually accompanied by a commentary to try to improve their educational value. The first Year In Review supplement was published in September and it is very much hoped that this will be regarded as a valuable addition to the journal and will continue to be produced in the years to come. The BTS abstracts will also be published as a supplement for the first time in December and this will allow more pages to be published within the main body of Thorax itself.

\section{The future}

Future changes to improve the journal include a new cover design, with the contents appearing inside the journal.

A new series entitled "Science Matters" will start early next year. These articles are by leading clinical scientists and explain advances that should be made familiar to the general respiratory reader. This series is now well under way and we have contributions commissioned for the next two years.

At the time of writing this report a new Editor is being sought. The experience of being the Editor of this prestigious journal has been most rewarding. Running the journal has been at times exciting, stimulating, frustrating and utterly relentless. However, the reward of seeing an issue produced at the beginning of each month has been the ultimate satisfaction. The journal has grown strongly over the last few years and looks secure both in terms of content and profit income. No one should underestimate the enormous amount of work that goes into making a journal successful, and I would like to express my thanks once again to all the Associate Editors for putting up with my continuing demands on their time. To Angela Betchley, the Editorial Assistant, I have to express a very large debt of gratitude for her quiet and efficient methods of running the journal, for dealing with all the technical matters so ably, and for shielding me from many of the day to day chores that running a journal entails. It would not have been possible to have enjoyed the Editorship so much without her help and encouragement. Finally I wish the next Editor(s) the very best of good fortune in taking this excellent journal onwards.

The reviewers who have made their own important contributions to the peer review system that is the lifeblood of the editorial process are gratefully acknowledged on page 1328 . 